Zitherarius Reflectionis

\title{
A VIVÊNCIA DA ÉTICA NAS ORGANIZAÇÕES PÚBLICAS: ALGUMAS CONSIDERAÇÕES
}

\author{
Edina Franco ROCHA. ${ }^{1}$ edinikla@ hotmail.com.
}

Resumo: Este artigo teve como objetivo apresentar algumas considerações sobre a vivência da ética nas Organizações Públicas, abordando a definição de ética e sua historicidade, os aspectos legais, e a ética na universidade. Baseado em pesquisa bibliográfica de alguns teóricos que abordam o tema. Procuramos definir o que é ética de acordo com alguns autores que embasam o nosso artigo, os vários pontos de vista, tratamos sobre a sua definição ao longo da história, e também dos aspectos legais. E finalizamos, fazendo algumas considerações finais sobre o tema abordado.

Palavras-chave: ética, moral, universidade.

\begin{abstract}
This article aims to present some considerations about the experience of ethics in Public Organizations, addressing the definition of ethics and its historicity, the legal aspects, and ethics at university. Based on a literature review of some theorists that address this issue, we tried to define what ethics is. We present the distinct points of view and deal with their definition throughout History, as well as the legal aspects. To conclude, we make some final reflections concerning the topic studied.
\end{abstract}

Keywords: ethics, moral, university

\footnotetext{
${ }^{1}$ Especializanda em Gestão de Pessoas nas Organizações Públicas, pela UFG/Campus Jataí. Graduada em Pedagogia (CAJ/UFG). Professora do Ensino Fundamental. Endereço eletrônico edinikla@hotmail.com.
} 


\section{Introdução}

A ética é um tema que suscita debates, dilemas e diferentes abordagens teóricas. Constitui-se em uma preocupação antiga do homem. Desde o surgimento da filosofia, a ética vem sendo abordada com ênfase. Para Valls, (2008, p.3), um comportamento correto eticamente é um comportamento adequado aos costumes vigentes de uma determinada sociedade. Para o autor, quem se comporta de maneira diferente, saindo dos costumes aceitos e respeitados pela maioria da sociedade, estaria errado.

Os valores éticos podem se transformar ao longo dos tempos, assim como a sociedade se transforma; com isso, a ética tem sido abordada em várias reflexões teóricas. Percebemos, então, que não são apenas os costumes que se modificam, mas também os valores que o acompanham.

$\mathrm{O}$ assunto a ser discorrido neste texto é sobre algumas considerações sobre a vivência da ética nas Organizações Públicas, levando-se em conta que as organizações são constituídas por sujeitos, de relações interpessoais, e que carregam consigo uma cultura diversificada.

Nesse sentido, abordaremos os aspectos legais que dizem respeito à vivência da ética como uma prática a ser exercida e incentivada na gestão de pessoas. Entre outras situações, a ética seria um fator muito importante nos processos de tomada de decisão que estão envolvidos dentro de uma organização pública. A ética é um fator preocupante, como nos diz Schulz (2005, p.1): “os sujeitos envolvidos nas gestões evidenciam uma crise ética pessoal e social, onde os padrões morais e decência tornaram-se caóticos".

Tomou-se como base para este estudo alguns teóricos que discutem o assunto, artigos, anais de congresso e textos que se referem à ética nas organizações públicas. $\mathrm{O}$ artigo está estruturado da seguinte forma: primeiro relatou-se, de acordo com vários autores, o que é ética; depois, a história da ética; em seguida, abordou-se a ética na universidade, finalizando com algumas considerações. 


\section{2. Ética ao longo da história}

Para iniciarmos a falar de ética, precisamos verificar o que significa ética. De acordo com Chauí (2007, p. 340), ética vem da palavra ethos, que é o caráter ou temperamento individual que deve ser educado para os valores da sociedade. Para a mesma autora, a ética é uma parte da filosofia que fala dos costumes e normas que regem uma sociedade, pois uma ética normativa é uma ética dos deveres e obrigações. Assim, um agente ético é um sujeito ético, um ser racional, consciente, livre e responsável. Para a autora, uma ação ética só é válida se for boa e justa.

A ética pode ser compreendida como "[...] teoria, investigação ou explicação de um tipo de experiência humana ou forma de comportamento dos homens [...]” (VÁZQUEZ, 2002 p. 16), e possui como função fundamental estudar a essência do comportamento moral, que é diferente da moral propriamente dita. Ainda segundo esse autor: "A ética estuda uma forma de comportamento humano que os homens julgam valioso e, além disto, obrigatório e inescapável” (VÁZQUES, 2002 p. 16).

De acordo com Ferreira (1998, p.733), “ética é o estudo dos juízos de apreciação referentes à conduta humana, suscetível de qualificação do ponto de vista do bem e do mal, seja relativamente a determinada sociedade."

De acordo com Max Weber, citado por Valls (2008, p.4), os protestantes valorizavam eticamente muito mais o trabalho e a riqueza. Já os católicos, valorizavam mais a abnegação, o espírito de pobreza e de sacrifício. Para Kant, citado por Valls (2008, p.4), a igualdade entre os homens era fundamental para o desenvolvimento de uma ética universal. Sua filosofia, de acordo com Valls (2008, p.4), era voltada sempre para o homem, buscando encontrar nele as condições de possibilidade do conhecimento verdadeiro e do agir livre. Assim, nas questões éticas, aparece o dever, ou obrigação moral, como sendo uma necessidade para uma liberdade.

Kant, citado por Valls (2008, p.5), discorre sobre uma necessidade de chegar a uma moral igual para todos, moral racional. Portanto, diante de cada lei, de cada ordem, de cada costume, o sujeito estaria obrigado a ser um homem livre, e agir de acordo com o seu dever. Segundo Platão (1993), um dos maiores filósofos da história grega, ele partia da ideia de que todos os homens buscavam a felicidade, o Sumo Bem. Para Aristóteles (2002), outro grande filósofo grego, existiam os bens em concreto para o homem, uma ética finalista e eudemonista, marcada pelos fins que devem ser 
alcançados para que o homem pudesse atingir a felicidade. Na sua grande obra, Ética a Nicômaco, aparecem coisas relativas e necessárias à construção de uma ética.

Na Ética a Nicômaco, Aristóteles (2002) afirma que o caráter é resultado de nossos atos, que adquirimos uma ou outra disposição ética agindo de uma ou outra maneira. Realizando coisas justas, assumiremos bons hábitos e o caráter torna-se justo; inversamente, agindo de maneira intemperante, adquire-se o hábito de ceder aos desejos e tornamo-nos intemperantes. O caráter não é mais o que recebe suas determinações da natureza, da educação, da idade e da condição social; é produto da série de atos dos quais sou o autor. Posso ser declarado autor de meu caráter, como o sou de meus atos: do mesmo modo que meus atos podem ser objeto de elogio, meu caráter pode ser objeto de louvor.

Ainda de acordo com sua obra, Ética a Nicômaco, vícios e virtudes não são simples traços psicológicos adquiridos, mas têm significado moral, porque pertencem ao campo daquilo que depende de nós. Esta responsabilidade testemunha a seriedade da ação. Ele diz: "quando ajo, não faço somente algo que terei que responder posteriormente, mas escolho o que vou ser". Quando agimos contra a regra do que conhecemos, como todo ser que recebeu uma educação formal, deixo-me tornar cego à lei, em não saber mais o que é o bem. Ele ainda discorre, dizendo que há uma distinção a ser introduzida na questão da responsabilidade humana, que seria o ato, que depende de mim, porque tenho um responsabilidade sobre as consequências; em compensação, não posso assumir todas as consequências indiretas dos hábitos que fiz. $\mathrm{O}$ autor ainda diz sobre o caráter, que por ele era considerado imputável, pois, agindo, não poderia ignorar que manipulasse seus hábitos, mas, enquanto dono dos meus atos, a cada instante, não posso transformar meu caráter a todo o momento: isso equivale a dizer que não tenho caráter. Para ele, o autor, dessa forma, parece que, no final de certo tempo, o caráter ficasse difícil de transformá-lo. Para Aristóteles(2002), feliz é aquele que vive as virtudes dentro da pólis. É aquele que vive uma vida intelectual, sendo capaz de dirigir bem a vida, deliberando de modo correto o que é bem ou mal para si. É o exercício dessa virtude que constitui a perfeição da atividade contemplativa, e dessa forma que é possível alcançar a felicidade máxima. A vida ideal e feliz é a vida racional; essa vida feliz supõe a estima de si mesmo e a amizade. 
Para os gregos, o ideal ético estava na busca e prática da ideia do bem. De acordo com Boff (2003),

\begin{abstract}
Os mestres do passado ,como Aristóteles, Platão e Santo Tomás Aquino, em suas construções éticas, partiam do projeto de felicidade [...] intrínseco aos seres humanos. Vivemos frustrados, pois se a felicidade é o que mais se busca e o markentig comercial mais a promete, é também o que menos se encontra [...] A felicidade não pode ser construída sobre a felicidade dos outros. Nem dá pra alguém sentir-se feliz quando constata a dramática infelicidade da maioria dos seres humanos e a crescente degradação dos ecossitemas. (BOFF, 2003, p.100)
\end{abstract}

Atualmente, a ética está no centro dos debates sobre os limites da ciência, que envolvem as organizações, os cidadãos em geral, os juristas, os religiosos, os profissionais de diversas áreas e as comunidades científicas. Pois a sociedade atual que nos é imposta, onde cada vez mais as pessoas são mais individuais e querem o poder e o dinheiro a qualquer preço, necessita de ética, de valores morais que direcionem as atitudes dos cidadãos que, a cada dia, estão mais preocupados com a competitividade e com consumo.

Segundo Chauí (2007, p.342), a sociedade fala do "retorno à ética", sobre o qual ela pontua várias explicações para esse termo: o vazio que a ideologia neoliberal criou a seu bel-prazer; a ampliação da acumulação do capital flexível; a naturalização e a valorização do sucesso a qualquer preço; as mudanças tecnológicas como forma de poder e de força produtiva; a sociedade das mídias e do consumo de bens supérfluos. Assim, para a autora, esse retorno seria arrumar essa confusão em que se encontra nossa sociedade, mudando os costumes e restaurando os valores de uma sociedade alienada e fragmentada em várias éticas, a ética na família, a ética na religião, a ética médica, a ética profissional.

Então, nas organizações, a ética não podia ser diferente, pois a discussão sobre ética organizacional começou na década de 80, tomando fôlego nos anos 90, no início do novo século. A ênfase no comportamento ético deixou de ser um modismo, porque as exigências internacionais estabeleceram padrões que precisam ser cumpridos por qualquer empresa brasileira que queira competir no mercado estrangeiro. Então, parte-se do princípio que a organização precisa se preocupar com todos os segmentos de públicos, como o colaborador, o fornecedor, o distribuidor, o cliente e com os seus 
relacionamentos, dentro de uma filosofia de comunicação organizacional que tenha como base a ética nos relacionamentos.

Neste contexto, Andrade (2009, p.5) fala que o profissional pode desempenhar papel fundamental, como responsável pelo gerenciamento dos relacionamentos com base em padrões éticos.

Dessa forma, é preciso compreender como as organizações se preocupam com as questões éticas e como devem fazer para realizar uma implantação bem-sucedida do conceito, sem os equívocos a que essa iniciativa está sujeita.

\section{Direitos e garantias legais}

A ética, assim como qualquer assunto que envolva um ou mais sujeitos, tem uma legislação que ampara e garante que seja cumprida. De acordo com Constituição Federal de 1988, no Capítulo I, Art. 5, “Todos são iguais perante a lei, sem distinção de qualquer natureza, garantindo-se aos brasileiros e aos estrangeiros residentes no País a inviolabilidade do direito à vida, à liberdade, à igualdade, à segurança e à propriedade".(BRASIL, 1988)

A Declaração Universal dos Direitos Humanos, no Artigo I, diz que: "todos os homens nascem livres e iguais em dignidade e direitos. São dotados de razão e consciência e devem agir uns para com os outros com espírito de fraternidade" (MOURA, 2004, p.103). Portanto, está na lei que devemos agir corretamente, e agir dessa maneira depende do que cada cultura considera o que é certo. No artigo XXVII, "Todos os homens têm direito à proteção dos interesses morais e materiais decorrentes de qualquer produção científica, literária ou artística de sua autoria” (MOURA, 2004, p.106).

De acordo com o Código de Ética Profissional do Servidor Público Civil, Cap. I, inciso II, “o servidor público não poderá jamais desprezar o elemento ético de sua conduta. Assim, não terá que decidir somente entre o legal e o ilegal, o justo e o injusto, o conveniente e o inconveniente, o oportuno e o inoportuno, mas principalmente entre o honesto e o desonesto" (AMOÊDO, 2007). No Inciso III, diz:

a moralidade da Administração Pública não se limita à distinção entre o bem e o mal, devendo ser acrescida da ideia de que o fim é sempre o bem comum. O equilíbrio entre a legalidade e a finalidade, na conduta do servidor público, é que poderá consolidar a moralidade do ato administrativo. 
Assim, percebemos que só o código de ética profissional não garante que a ética seja instaurada ou resgatada nas organizações, sendo preciso cultivar os valores éticos, vivenciando e agindo eticamente. Então, a necessidade de viver a ética nas organizações públicas é urgente, pois o que vemos, na maioria dos lugares em que convivemos, são pessoas preocupadas mais em passar por cima das outras, em ter vantagem em tudo e, a cada dia, ter mais poder. Para isso, fazem de tudo, até esquecem que existe a ética. Ética essa, que tentaremos dar o real valor neste artigo.

Alguns autores nos ajudam a pensar o que seria essa vivência da ética nas organizações, como Romaro (2008, p.40) que diz que a ética é "a possibilidade de refletir, de se responsabilizar, muitas vezes de ousar, ousar a pensar, questionar, ao outro e a si”. Devemos pensar na ética não só quando fere aos nossos interesses, mas também quando transgredimos algo que fere o interesse do outro.

De acordo com Amoêdo (2007), que redigiu o código de ética do servidor público, no seu Cap. II, das Comissões de Ética, (FALTA O ARTIGO, CONSTANDO SÓ O INCISO) XVI,

Em todos os órgãos e entidades da Administração Pública Federal direta, indireta, autárquica e fundacional, ou em qualquer órgão ou entidade que exerça atribuições delegadas pelo poder público, deverá ser criada uma Comissão de Ética, encarregada de orientar e aconselhar sobre a ética profissional do servidor, no tratamento com as pessoas e com o patrimônio público, competindo-lhe conhecer concretamente de imputação ou de procedimento susceptível de censura.(AMOÊDO, 2007)

Então, podemos verificar que o que tange à lei, estamos amparados nos direitos e deveres relativos à ética, falta vivenciá-la, para que faça sentido nas relações interpessoais, nas organizações públicas. Romaro (2008), ao analisar o Código de Ética Profissional do Psicólogo, diz:

Percebemos que quase todos os artigos e alíneas baseiam-se nos princípios de Não Maleficência, Beneficência, Autonomia e Justiça, buscando sempre minimizar os riscos envolvidos em quaisquer procedimentos, sejam estes de pesquisa ou não, maximizando os benefícios, respeitando a autonomia, a possibilidade de escolha, a individualidade e o tratamento igualitário, garantindo condições de sigilo, privacidade e confidencialidade.(ROMARO, 2008, p.42)

\section{2. Ética na Universidade}


A ética vem sendo tratada, conforme acima citado, como uma preocupação do mundo atual nas organizações. E a universidade não poderia ficar fora, pois é onde se faz as transformações e são seguidos os modelos, onde se formam os modelos a serem seguidos.

A ética é um princípio a ser incorporado nas universidades, podendo as pessoas serem incentivadas a adotarem padrões éticos. Assim, existem várias maneiras de se fazer isso, e uma dessas maneiras seria adotar nos cursos de formação de futuros gestores - e um deles seria o de Administração - debates e discussões sobre a ética. De acordo Zykbersztajn (2002, p.5), alguns autores criticam os cursos de Administração por negligenciarem o tema e apontam a tendência de retomada da sua importância nos cursos de negócios.

Outra maneira de verificar a preocupação da universidade com o resgate da ética, seria a preocupação com os códigos de conduta nas organizações, ainda de acordo com o mesmo autor. Pois, através dele, seria possível orientar as pessoas a como se comportar eticamente e a punir quem não cumprir o combinado no código de conduta.

Mas isso não seria necessário se as pessoas adotassem esses princípios de livre espontânea vontade, como uma necessidade para a vida coletiva. Portanto, esse tipo de código é necessário para uma convivência melhor, eticamente falando. E, às vezes, ou quase sempre, as organizações acabam adotando esses códigos de ética somente para criarem uma imagem boa perante a sociedade ou para se resguardarem legalmente (ZYKBERSZTAJN, 2002, p.6).

Cabe aos indivíduos quererem resgatar essa ética na sua vida pessoal e trazê-la para as organizações em que trabalham, em que convivem a maior parte do tempo. $\mathrm{E}$ isso está intimamente ligado à cultura de cada organização, de cada universidade.

A cultura é a melhor forma de compreendermos os indivíduos; ela funciona como um termômetro de verificação dos padrões coletivos em um grupo. Através dela, podemos ver a maneira de percepção, de pensar, de sentir e agir de uma organização. De acordo com Pires (2005, p.2), a definição de cultura seria mais que um conjunto de regras, de hábitos e de artefatos, seria, pois, a construção de significados partilhados pelo conjunto de pessoas que pertencem a um mesmo grupo. 
Na universidade, os indivíduos que prestam serviços estão em prol da construção do conhecimento, servindo os acadêmicos nas suas necessidades, incentivando a pesquisa e fazendo uma extensão com a comunidade. Para tal, é necessário pensarmos qual seria a cultura da universidade que está a serviço dessa comunidade? Estariam os profissionais da universidade, agindo eticamente no trabalho, ou simplesmente executando tarefas como meros funcionários públicos?

Estas indagações nos remetem a pensar na ética como sendo necessária na vida do indivíduo, devendo ser pensada e cultivada dentro da universidade pública, e isso só poderá ser feito através da educação.

De acordo com Pires (2005, p.2) as organizações estão inseridas num ambiente, que recebe influências e influencia pessoas. Portanto, a universidade está cheia de diferentes culturas, que são componentes que formam a cultura organizacional. A universidade recebe diferentes maneiras de pensar e agir, formando a cultura presente. É por meio da interação entre as pessoas que se definem os propósitos das organizações.

O termo cultura organizacional surgiu, primeiro, na literatura de língua inglesa, nos anos 60, que significava clima. Assim, a literatura técnica específica adotou esse termo, de acordo com Pires (2005, p.2). Mesmo assim, não há uma concordância para a definição do termo. Mas vários autores concordam que cultura organizacional é a base da organização. São os valores e crenças em comum.

Pires (2006, p.3) vem dizer que: "a cultura organizacional é um conceito essencial à construção das estruturas organizacionais[...] será um conjunto de características que diferencia em relação a qualquer outra”. Uma organização, uma universidade, é aquilo que sua cultura organizacional mostra no dia-a-dia, através de seus indivíduos; se forem éticos, a universidade também é ética, se agirem eticamente, a universidade age eticamente.

Mesmo considerando que não é possível ter uma ética individual comum a todos, devemos refletir sobre a possibilidade de induzir ou incorporar padrões éticos nas organizações. Assim, o melhor caminho a ser seguido é criar instrumentos de gestão de ética ou para ética.

Nesse sentido, de acordo com Pereira (s.d., p. 4), tudo estaria voltado para a gestão de pessoas, de como os sujeitos estariam sendo levados a conduzir a ética, 
explicitando dentro das tomadas de decisão diárias. Seria como valorizar alguns aspectos dentro da gestão, que colocariam a ética como um dos eixos da organização. E, para isso, seriam necessários os seguintes elementos: valores éticos, normas de condutas, gestão, orientação e controle.

De acordo com Pereira (s.d., p. 4), as normas de condutas seriam um dos principais elementos dentro dessa construção ética, devendo ser aderidas pelos sujeitos pelo compromisso moral e não imposto, isso para ter uma efetiva validade. Para que isso ocorra, o autor diz que precisamos de pessoas que façam acontecer, que seriam os líderes, os gestores e a alta administração nas instituições, que funcionariam como multiplicadores de condutas éticas, dentro de uma estratégia de gestão de ética. As suas práticas devem ser de acordo com os valores éticos da Administração Pública. Mas é importante para os servidores conhecerem seus direitos e obrigações quando não agirem dentro das normas de conduta estipuladas. As normas de conduta devem ser claras, e as políticas de administração dos recursos humanos da instituição devem trabalhar para que isso ocorra.

\section{Considerações finais}

A ética deveria representar um valor para a sociedade moderna, mas temos muito o que avançar nesse sentido de comportamento dos indivíduos, da universidade como uma organização pública. Pois são nas organizações ou nos grupos em que estão inseridos que vemos comportamentos humanos indevidos eticamente.

Mudanças nas atitudes dos indivíduos poderiam ser um elemento importante para o desenvolvimento na área da ética nas organizações. Mesmo que tenha um código de ética que dita as normas e condutas a serem seguidas, por si só, esse código não vale de nada. De acordo com Arruda (2005, p.35), os códigos de éticas profissionais são importantes, pois estabelecem padrões de conduta como meio de disciplinar a atuação nas organizações. “A empresa necessita desenvolver-se de tal maneira que a ética, entendida como a conduta ética de seus empregados e os valores e crenças primordiais da organização, torne-se parte de sua cultura" (ARRUDA, 2005, p.36). O código de ética necessita de ser pensado e incorporado pelas pessoas que constituem as organizações públicas, de acordo com cada cultura trazida de suas famílias, não ferindo 
nenhuma, mas criando, em cima dessas, outra, que daria um suporte para todas as questões éticas em geral, com educação e uma formação para tal.

Diante do que pesquisamos, consideramos que a ética seria uma necessidade a ser incorporada na organização pública, algo a ser cultivado e ensinado através da educação. De acordo com Oliveira (2004, p.70), "pensar a ética e a educação do ponto de vista cultural significa refletir historicamente essas realidades inseparáveis do

processo e da construção de existência humana.” É preciso educar para um ética nas organizações, educar os indivíduos numa cultura pluralista.

Para o autor Oliveira (2004, p.79), "a educação ética é uma arte que deve ser construída pela lógica do pensamento, pela reflexão, pelo raciocínio e pela inteligência do homem." Então, não seria um pensamento ou uma atitude construída rapidamente, mas sim ao longo da vida do ser humano, do indivíduo que faz parte dessa organização pública, a universidade. Ainda segundo o mesmo autor, "a vida ética depende da vontade humana da disciplina e da formação, portanto, depende essencialmente do trabalho que a educação realiza" (OLIVEIRA, 2004, p.80).

De acordo com Kant (1996, p.15), “o homem não pode se tornar um verdadeiro homem senão pela educação. Ele é aquilo que a educação dele faz." O indivíduo é o que sua educação é, ele reflete o que aprendeu com a educação.

\section{Referências Bibliográficas:}

AMOÊDO, Sebastião. Ética no trabalho na era da pós-qualidade. Qualitymark, 2007.

ANDRADE, Zilda Aparecida Freitas de. Relações Públicas: construindo relacionamentos éticos nas organizações. 2009. Disponível em: www.portalrp.com.br/projetosacademicos/conceituais01/0091.pdf Acesso em 22 de maio de 2010 às 10:40.

ARISTÓTELES. A ética a Nicômaco. São Paulo: Martin Claret, 2002.

ARRUDA, Maria Cecília Coutinho de. A contribuição dos códigos de ética profissional às organizações brasileiras. Revista $E \& G$ Economia e Gestão, Belo Horizonte, v.5, n.9, p. 35-47, abr. 2005.

BOFF, Leonardo. Ética e moral: a busca dos fundamentos. Petrópolis, RJ: Vozes, 2003. 
CHAUÍ, Marilena. Cultura e democracia: o discurso competente e outras falas. 12 ed. São Paulo: Cortez, 2007.

CONSTITUIÇÃO DA REPÚBLICA FEDERATIVA DO BRASIL, 1998. Texto institucional de 5 de outubro de 1988 com as alterações adotadas pelas Emendas Constitucionais de n. 1 de 1992, a 46, de 2005.

FERREIRA, A. B. de H. Novo dicionário da língua portuguesa. 2. ed. rev. amp. Rio de Janeiro: Editora Nova Fronteira, 1998.

KANT, Immanuel. Sobre a pedagogia. Trad. Francisco Cok Fontanella. Piracicaba: UNIMEP, 1996.

MOURÃO, Roldão Alves. Ética no meio ambiente do trabalho. São Paulo: Editora Juarez de Oliveira, 2004.

OLIVEIRA, José Sílvio de. Ética, educação e escola. Dissertação de Mestrado. Universidade Federal de Goiás/Faculdade de Educação. Goiânia, 2004.

PEREIRA, Romilson Rodrigues. ÉTICA NAS INSTITUIÇÕES PÚBLICAS. Ensaio. s.d. Disponível em portal2.tcu.gov.br/portal/pls/portal/docs/781700.pdf Acesso em 22 de maio de 2010 às 10:24.

PIRES, José Calixto de Souza; MACEDO, Kátia Barbosa. Cultura organizacional em organizações públicas no Brasil. Rev. Adm. Pública, Rio de Janeiro, v. 40, n. 1, fev. 2006 . Disponível em <http://www.scielo.br/scielo.php?script=sci_arttext\&pid=S0034$76122006000100005 \& \operatorname{lng}=$ pt\&nrm=iso>. Acesso em 22 de maio de 2010 às 10:15.

PlATÃo. A Repúlica. Tradução de Maria Helena Rocha Pereira. Lisboa: Fundação Calouste Gulbenkian, 1993.

ROMARO, Rita Aparecida. Ética na psicologia. Petrópolis: Vozes, 2008.

SCHULZ, Almiro. Gestão e Ética. Texto apresentado no VII Encontro de Pesquisa em Educação da Região Centro-Oeste - EPECO, Curitiba, 2005, (Apostila).

VALLS, Álvaro L. M. O que é ética. São Paulo: Brasiliense, 2008. - (Coleção Primeiros Passos; 177) 9.ed. de 1994.

VASQUEZ, Adolfo Sanches. 22.ed. Ética. João Dell'Anna. Rio de Janeiro: Civilização Brasileira, 2002.

WILLERS, Ednilse Maria. CRUZATTI, Maria A. P. A necessidade da ética nas organizações atuais. Disponível em

revista.unioeste.br/index.php/expectativa/article/download/.../422 acesso em 22/08/2009 às 16:47.

ZYLBERSZTAJN, Decio. Organização ética: um ensaio sobre comportamento e estrutura das organizações. Rev. adm. contemp., Curitiba, v. 6, n. 2, ago. 2002 . 
Disponível em <http://www.scielo.br/scielo.php?script=sci_arttext\&pid=S141565552002000200008\&lng=pt\&nrm=iso >. acessos em 22 maio 2010 às 10:15. 